\title{
Negative impact of low body mass index on liver cirrhosis patients with hepatocellular carcinoma
}

\author{
Qinggang $\mathrm{Li}^{1 *+} \mathbb{D}$, Hui Xing ${ }^{2+}$, Dan Liu ${ }^{2}$ and Hui Li
}

\begin{abstract}
Background: The impact of obesity on the prognosis of hepatocellular carcinoma (HCC) has not been well characterized in a Chinese population. Therefore, the aim of this study was to examine the influence of BMI on the clinicopathological characteristics and mortality of patients with HCC.

Methods: The study cohort consisted of 379 patients who were diagnosed with HCC at the First Affiliated Hospital of Harbin Medical University between June 2012 and August 2014. Study subjects were divided into two body mass index (BMl) categories: normal weight (BMl $<23 \mathrm{~kg} / \mathrm{m}^{2}$ ) and overweight (BMl $\left.\geq 23 \mathrm{~kg} / \mathrm{m}^{2}\right)$.

Results: Of the 379 patients, $44(11.6 \%)$ were underweight $\left(<18.5 \mathrm{~kg} / \mathrm{m}^{2}\right), 172(45.4 \%)$ had a normal weight $(18.5 \leq \mathrm{BMl}<23.0), 133$ (35.1\%) were overweight $(23.0 \leq \mathrm{BMl}<27.5)$, and $30(7.9 \%)$ were obese $(\mathrm{BMI} \geq 27.5)$. After a median follow-up time of 296 (range, 15-720) days, 168 (44.3\%) patients died with median survival time of 159 (range, 15-690) days. Patients with lower BMls also exhibited a higher liver-related mortality rate (60.6 vs. 22.7 \%; $p=1.8 \times 10^{-13}$ ) and a shorter survival time (353 days vs. 571 days; $p=6.2 \times 10^{-6}$ ) than patients with higher BMIs. In multivariate analysis, the BMI class was also found to be a significant independent impact factor for overall survival $\left(p=2.2 \times 10^{-8}\right)$, age, alpha-fetoprotein level, Child-Pugh score, treatment strategy, antiviral treatment, extrahepatic metastasis, and tumor infiltration of the portal vein.
\end{abstract}

Conclusions: Our data suggest that lower BMI has a significant impact regarding poor outcomes in patients with HCC. To better understand the impact of BMI on the prognosis of HCC patients, more large-scale cohort studies will be necessary.

Keywords: Hepatocellular carcinoma, Body mass index, Prognosis, Mortality

\section{Background}

Hepatocellular carcinoma (HCC) is a major global health burden and is the fifth most commonly diagnosed cancer in the world [1]. Its incidence and mortality have largely reflected the prevalence of hepatitis B (HBV) and $\mathrm{C}(\mathrm{HCV})$ viral infections, particularly in China. Recently, obesity has been found to be related to a variety of cancers including pancreatic cancer, colorectal cancer, and esophageal cancer [2-4]. Epidemiological data has shown that obesity not only increases the risk and progression of both $\mathrm{HBV}$ - and HCV-associated cirrhosis and HCC, but also is associated with non-B non-C HCC [5]. Moreover, the im-

\footnotetext{
* Correspondence: Leeqg@163.com

${ }^{\dagger}$ Equal contributors

'Department of Infectious Disease, First Affiliated Hospital of Harbin Medical University, No. 23 You Zheng Street, Harbin 150001, People's Republic of China

Full list of author information is available at the end of the article
}

pact of obesity on the prognosis of HCC has not been well characterized in Chinese populations. Consequently, in the present study, we explored the significance of body mass index (BMI)-defined obesity on the survival of HCC patients in a Chinese population.

\section{Methods \\ Patients}

A total of 379 patients with liver cirrhosis diagnosed histologically or by typical clinical signs, diagnosed with HCC at the First Hospital of Harbin Medical University between June 2012 and August 2014, were studied retrospectively. A diagnosis of HCC was based on typical CT findings, namely hyperattenuation in the arterial phase and hypoattenuation in the equilibrium phase. HCC stages were classified according to the Barcelona Clinic Liver Cancer (BCLC) staging system [6]. Patients 
with a previous cancer history and those suspected of having metastatic hepatic cancer were excluded from our study. Written consent was obtained from each of our patients. The study was approved by the local ethics committee of the First Hospital of Harbin Medical University.

\section{Data collection}

We recorded the following clinical data upon first admission and diagnosis in our department: age; sex; BMI; smoking and alcohol consumption history (ever or never); presence of diabetes mellitus; hepatitis infection status (HBV, HCV, HBV + HCV or none); Child-Pugh classification; BCLC stage; history of previous hepatitis treatment; and alpha-fetoprotein (AFP) level. Body weight was measured on admission. BMI was calculated as weight divided by height squared $\left(\mathrm{kg} / \mathrm{m}^{2}\right)$. According to the WHO classification for Asian populations, the patients were categorized as underweight (BMI <18.5), normal weight $(18.5 \leq \mathrm{BMI}<23.0)$, overweight $(23.0 \leq \mathrm{BMI}<27.5)$, and obese (BMI $\geq 27.5$ ) [7]. Because the number of patients in the underweight group and the obese group was

Table 1 Baseline characteristics of study patients according to BMI

\begin{tabular}{|c|c|c|c|c|}
\hline Characteristic & All cases & Normal weight $\left(\mathrm{BMl}<23 \mathrm{~kg} / \mathrm{m}^{2}\right)$ & Overweight (BMI $\geq 23 \mathrm{~kg} / \mathrm{m}^{2}$ ) & $p$ value \\
\hline No. of patients & $379(100 \%)$ & $216(57.0 \%)$ & $163(43.0 \%)$ & \\
\hline Age, years & $63.4 \pm 11.7$ & $64.0 \pm 11.5$ & $62.6 \pm 11.8$ & 0.199 \\
\hline Gender, male & $219(57.6 \%)$ & $116(53.0 \%)$ & $103(47.0 \%)$ & 0.064 \\
\hline Diabetes & $71(18.7 \%)$ & 35 (49.3\%) & $36(50.7 \%)$ & 0.147 \\
\hline Alcohol & 95 (25.1\%) & $54(56.8 \%)$ & 41 (43.2 \%) & 0.973 \\
\hline Smoking & $120(31.7 \%)$ & 74 (61.7\%) & 46 (38.3\%) & 0.211 \\
\hline AFP $\geq 400 \mu \mathrm{g} / \mathrm{L}$ & $228(60.2 \%)$ & 71 (31.1\%) & $157(68.9 \%)$ & 0.760 \\
\hline Viral status & & & & 0.691 \\
\hline HBV & $237(62.5 \%)$ & $134(56.5 \%)$ & $103(43.5 \%)$ & \\
\hline $\mathrm{HCV}$ & $125(33.0 \%)$ & $70(56 \%)$ & $55(44 \%)$ & \\
\hline $\mathrm{HBV}+\mathrm{HCV}$ & $1(0.3 \%)$ & $1(100 \%)$ & $0(0 \%)$ & \\
\hline None & $16(4.2 \%)$ & $11(68.8 \%)$ & $5(31.2 \%)$ & \\
\hline Previous treatment & & & & 0.717 \\
\hline Yes & $113(31.1 \%)$ & $66(58.4 \%)$ & 47 (41.6\%) & \\
\hline No & $250(68.9 \%)$ & $139(55.6 \%)$ & $111(44.4 \%)$ & \\
\hline Child-Pugh class & & & & $2.7 \times 10^{-4}$ \\
\hline A & 99 (26.1\%) & 44 (44.4 \%) & 55 (55.6\%) & \\
\hline B & 107 (28.2 \%) & $57(53.3 \%)$ & 50 (46.7\%) & \\
\hline C & $173(45.6 \%)$ & $115(66.5 \%)$ & 58 (33.5 \%) & \\
\hline Extrahepatic metastasis & & & & 0.113 \\
\hline Yes & $36(9.5 \%)$ & 25 (69.4\%) & 11 (30.6\%) & \\
\hline No & 343 (90.5 \%) & $191(55.7 \%)$ & $152(44.3 \%)$ & \\
\hline Infiltration of portal vein & & & & 0.304 \\
\hline Yes & $139(36.7 \%)$ & $84(60.4 \%)$ & 55 (39.6\%) & \\
\hline No & $240(63.3 \%)$ & $132(55.0 \%)$ & $108(45.0 \%)$ & \\
\hline Treatment after diagnosis & & & & $1.3 \times 10^{-4}$ \\
\hline Yes & $151(39.8 \%)$ & $68(45.0 \%)$ & $83(55.0 \%)$ & \\
\hline No & $228(60.2 \%)$ & $148(64.9 \%)$ & 80 (35.1\%) & \\
\hline BCLC stage & & & & $8.2 \times 10^{-5}$ \\
\hline 0 stage & $10(2.6 \%)$ & $3(30.0 \%)$ & $7(70.0 \%)$ & \\
\hline 1 stage & $64(16.9 \%)$ & $28(43.8 \%)$ & 36 (56.2 \%) & \\
\hline 2 stage & 78 (20.6\%) & 38 (48.7\%) & 40 (51.3\%) & \\
\hline 3 stage & $54(14.2 \%)$ & $32(59.3 \%)$ & 22 (40.7 \%) & \\
\hline 4 stage & $173(45.6 \%)$ & $115(66.5 \%)$ & $58(33.5 \%)$ & \\
\hline
\end{tabular}


Table 2 Overall survival for various characteristics based on Kaplan-Meier analysis

\begin{tabular}{|c|c|c|}
\hline Variables & $\begin{array}{l}\text { Overall survival }(d) \\
\text { mean }(95 \% \mathrm{Cl})\end{array}$ & $p$ \\
\hline BMI & & $3.6 \times 10^{-13}$ \\
\hline$<23 \mathrm{~kg} / \mathrm{m}^{2}$ & 353.9 (316.9-391.0) & \\
\hline$\geq 23 \mathrm{~kg} / \mathrm{m}^{2}$ & $571.8(532.3-611.4)$ & \\
\hline Age & & 0.924 \\
\hline$<60$ years & $444.9(397.6-492.1)$ & \\
\hline$\geq 60$ years & $444.2(406.8-481.5)$ & \\
\hline Gender & & 0.537 \\
\hline Male & $451.9(413.7-490.2)$ & \\
\hline Female & $427.2(382.8-471.6)$ & \\
\hline Diabetes & & 0.563 \\
\hline Yes & $440.6(408.3-474.0)$ & \\
\hline No & $457.2(388.0-526.5)$ & \\
\hline Alcohol & & 0.453 \\
\hline Ever & $425.8(369.4-482.1)$ & \\
\hline Never & $451.4(417.1-485.6)$ & \\
\hline Smoking & & 0.085 \\
\hline Ever & $411.6(362.2-461.1)$ & \\
\hline Never & $462.1(425.9-498.3)$ & \\
\hline AFP & & 0.651 \\
\hline$\geq 400 \mu \mathrm{g} / \mathrm{L}$ & $456.8(405.2-508.4)$ & \\
\hline$<400 \mu \mathrm{g} / \mathrm{L}$ & 433.7 (396.3-471.1) & \\
\hline Viral status & & 0.349 \\
\hline HBV & $432.8(396.0-469.6)$ & \\
\hline $\mathrm{HCV}$ & $459.8(408.3-511.3)$ & \\
\hline Previous treatment & & 0.502 \\
\hline Yes & $459.8(405.3-514.3)$ & \\
\hline No & 432.7 (396.9-468.5) & \\
\hline Child-Pugh class & & $3.6 \times 10^{-31}$ \\
\hline A class & $627.1(592.0-662.2)$ & \\
\hline B class & $479.7(435.0-524.5)$ & \\
\hline C class & 232.0 (198.9-265.2) & \\
\hline Extrahepatic metastasis & & $5.3 \times 10^{-13}$ \\
\hline Yes & 202.4 (148.4-256.4) & \\
\hline No & $471.2(440.7-501.7)$ & \\
\hline Infiltration of portal vein & & $1.4 \times 10^{-13}$ \\
\hline Yes & 259.9 (228.0-290.8) & \\
\hline No & $513.2(479.2-547.1)$ & \\
\hline Treatment after diagnosis & & $2.5 \times 10^{-31}$ \\
\hline Yes & $617.2(589.2-645.2)$ & \\
\hline No & 259.7 (232.5-286.9) & \\
\hline
\end{tabular}

Table 2 Overall survival for various characteristics based on Kaplan-Meier analysis (Continued)

\begin{tabular}{lll}
\hline BCLC stage & & $1.4 \times 10^{-36}$ \\
0 stage & $696.3(652.7-739.8)$ & \\
1 stage & $678.8(653.2-704.4)$ & \\
2 stage & $544.8(500.2-589.4)$ \\
3 stage & $299.6(257.9-341.2)$ \\
4 stage & $232.0(198.9-265.2)$ \\
\hline
\end{tabular}

small, we divided all patients into two groups based on a BMI above or below 23.0 [8].

\section{Statistical analysis}

All statistical analyses were carried out using SPSS version 17 (SPSS Inc. Chicago Illinois, USA) software. Differences in clinical features were assessed using the chi-square and Mann-Whitney $U$ tests and ANOVA for continuous variables. A survival analysis was performed using the Kaplan-Meier procedure and compared with the log-rank test results. All $p$ values were two-sided.

\section{Results}

\section{Patient characteristics}

Of the 379 eligible patients, $44(11.6 \%)$ were underweight $\left(<18.5 \mathrm{~kg} / \mathrm{m}^{2}\right), 172(45.4 \%)$ had a normal weight $(18.5 \leq \mathrm{BMI}<23.0), \quad 133 \quad(35.1 \%) \quad$ were overweight $(23.0 \leq \mathrm{BMI}<27.5)$, and $30(7.9 \%)$ were obese (BMI $\geq 27.5)$. The median BMI of the entire cohort was 22.6 (14.8-34.1). Two hundred and sixteen $(57.0 \%)$ patients were included in the normal weight group (BMI <23.0) and $163(43.0 \%)$ in the overweight group (BMI $\geq 23.0$ ). Baseline characteristics and clinicopathological features are detailed in Table 1.

Mean patient age was $63.4 \pm 11.7$ years. HBV (62.5\%) infection was more prevalent than HCV in our cohort. After admission, $39.8 \%$ of patients (151 cases) received surgery and/or transarterial chemoembolization treatment. The BCLC stage distribution was as follows: stage 0, 10 (12.6\%); stage A, 64 (16.9\%); stage B, 78 (20.6\%); stage C, 54 (14.2\%); and stage D, 173 (45.6\%). Other baseline characteristics are detailed in Table 1.

\section{Association of BMI with clinicopathologic variables}

We examined the association between the categorical BMI and clinicopathologic variables (Table 1). In patients with advanced Child-Pugh scores and BCLC stages a trend towards lower weight was observed $\left(p=2.7 \times 10^{-4}\right.$ and $p=8.2 \times 10^{-5}$, respectively). Of the $379 \mathrm{HCC}$ patients, $52(13.7 \%)$ had undergone surgical therapy and 116 (30.6\%) had received TACE treatment, including 17 who had received surgery as well as TACE. As 
detailed in Table 1, HCC patients who had undergone curative treatment had a tendency towards higher BMIs $\left(p=1.3 \times 10^{-4}\right)$.

\section{Impact of BMI on the prognosis of patients with $\mathrm{HCC}$}

After a median follow-up time of 296 (range, 15-720) days, $168(44.3 \%)$ patients had died with a median survival time of 159 (range, 15-690) days. Univariate analysis revealed that categorical Child-Pugh score and BCLC stage were significantly associated with overallsurvival time. In particular, patients with higher ChildPugh scores and BCLC stages had significantly shorter overall survival times as compared with lower-category patients $\left(p=3.6 \times 10^{-31}\right.$ and $p=1.4 \times 10^{-36}$, respectively; Table 2). Similarly, median overall survival was shorter in patients with distant metastasis and infiltration of the portal vein (Table 2). Patients with HCC who received surgery and/or TACE treatment had a better clinical outcome $\left(p=2.5 \times 10^{-31}\right.$; Table 2$)$. In addition, patients with a lower BMI also exhibited a higher liver-related mortality rate (60.6 vs. $22.7 \%$; $p=1.8 \times 10^{-13}$; Table 2$)$ and shorter survival time (353 vs. 571 days; $p=6.2 \times 10^{-6}$ ) than patients with a higher BMI; this suggested that the BMI was a complementary predictor of poor prognosis in patients with HCC. As shown in Fig. 1, we found that patients with a higher BMI tended to have a longer overall survival $\left(p=3.6 \times 10^{-13}\right.$; Table 2$)$.
We performed multivariate analysis to identify factors that were independently associated with all-cause mortality. In multivariate analysis, BMI class was also found to be a significant independent impact factor regarding overall survival $\left(p=2.2 \times 10^{-8}\right)$, age, AFP, Child-Pugh score, treatment strategy, antiviral treatment, extrahepatic metastasis, and tumor infiltration of the portal vein (Table 3).

\section{Discussion}

Worldwide, the incidence of individuals with excessive body weight or obesity has increased markedly over the past decades. BMI has long been considered an important factor in predicting the prognostic outcome in patients with many types of cancer including colon, pancreatic, and esophageal. In HCC, the results of limited studies regarding the influence of obesity on treatment outcome are unclear. For instance, a high BMI is well established as a prognostic factor for poor survival. In a study that included 328 consecutive patients with primary HCC and 60 patients with recurrent HCC, patients in the obese group were reported to exhibit significantly poorer long-term prognosis than those in the non-obese group [9]. In contrast, a study by Okamura et al. reported that a low BMI was a significant prognostic factor for low overall survival after hepatectomy for HCC [10]. These discrepancies may have resulted from the difference in BMI category between the two study

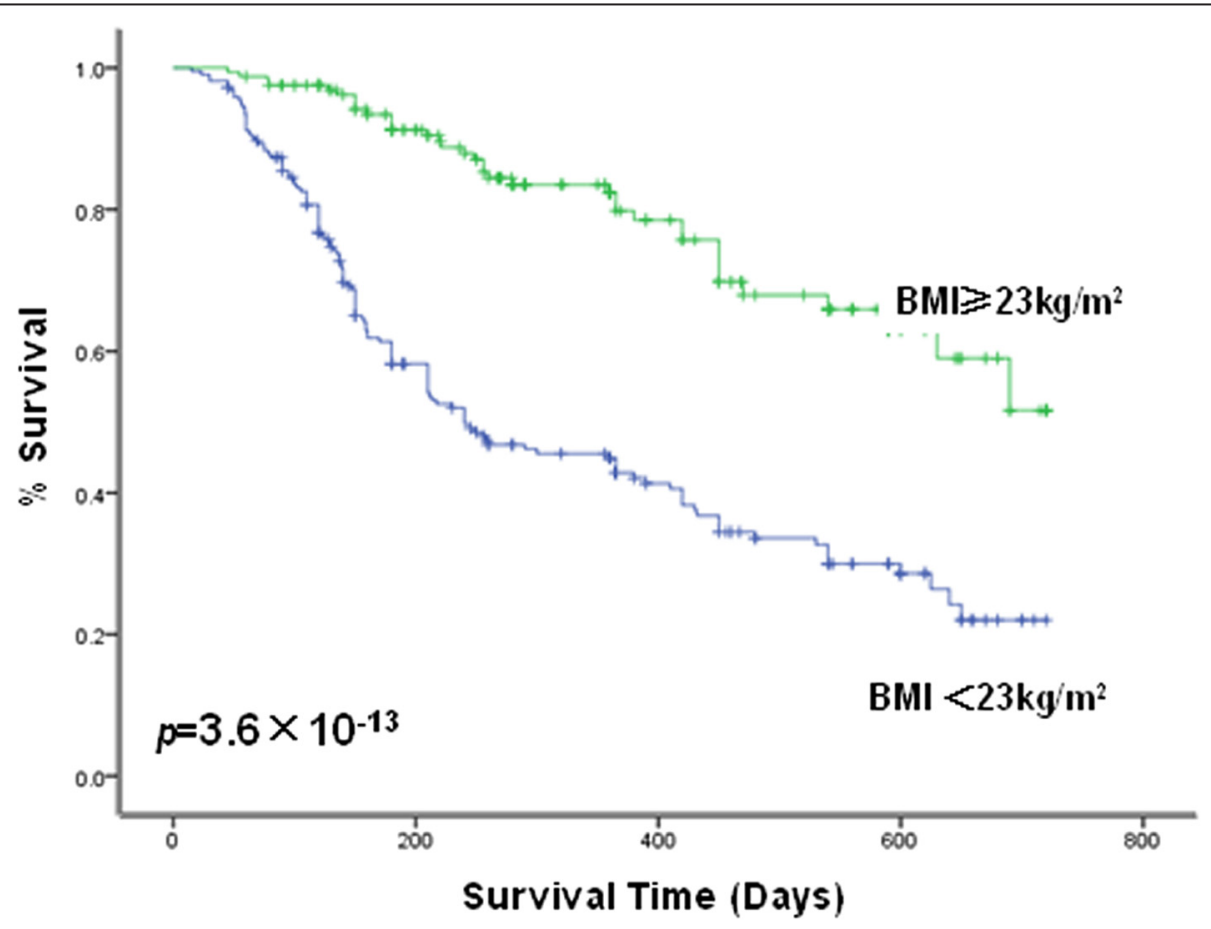

Fig. 1 Relationship between BMI and prognosis of patients with HCC. Kaplan-Meier survival analysis demonstrating low BMI was significantly related to poor prognosis 
Table 3 Prognostic indicators of overall survival using multivariate analysis

\begin{tabular}{llll}
\hline Variables & $\operatorname{Exp}(\mathrm{B})$ & $95 \%$ confidence interval & $p$ \\
\hline Age & 1.123 & $0.876-1.439$ & 0.360 \\
AFP & 1.123 & $0.836-1.508$ & 0.443 \\
Child-Pugh stage & 2.187 & $1.567-3.052$ & $4.2 \times 10^{-6}$ \\
Treatment strategy & 3.193 & $1.748-5.832$ & $1.6 \times 10^{-4}$ \\
Portal invasion & 0.772 & $0.535-1.112$ & 0.164 \\
BMl class & 0.347 & $0.239-0.502$ & $2.2 \times 10^{-8}$ \\
Extrahepatic metastasis & 2.154 & $1.412-3.287$ & $3.7 \times 10^{-4}$ \\
Antiviral treatment & 1.330 & $0.942-1.878$ & 0.105 \\
\hline
\end{tabular}

populations. In the latter study [10], the subjects were divided using a BMI of 18.5; patients with a low BMI of $<18.5$ were commonly in a more vulnerable immunological state and had a higher frequency of more malignant $\mathrm{HCC}$.

Several factors have been identified that influence the outcome of patients with HCC. Number and size of hepatic tumors, portal infiltration, metastasis, Child-Pugh score, and treatment algorithm are established impact factors regarding the survival of $\mathrm{HCC}$ patients $[6,11]$. Malnutrition is a factor that has an important negative influence on the clinical performance status of patients with liver cirrhosis in addition to malignant disease. Merli et al. found that patients with impaired nutritional status did less well concerning liver transplantation [12]. In our study, we found that patients with a higher BMI had lower rates of liver-related mortality relative to patients with a lower BMI. Moreover, patients with a higher BMI showed a trend towards better overall survival in multivariate analysis. Therefore, BMI may be linked to the nutritional status of $\mathrm{HCC}$ patients and influence the prognostic outcome.

BMI is a simple measurement based on individual weight and height, and is widely used. However, some investigators have identified that calculation of the BMI is not suitable for the identification of malnourished patients with HCC, and that differences in body composition rather than in BMI may be a true determinant of prognosis. In this regard, Fujiwara et al. measured the skeletal muscle index, mean muscle attenuation, visceral adipose tissue index, subcutaneous adipose tissue index, and visceral-to-subcutaneous adipose tissue area ratios using CT rather than the BMI endpoint. They concluded that sarcopenia, intramuscular fat deposition, and visceral adiposity can independently predict mortality in patients with HCC [13]. However, these measurements are anthropometrically more difficult in clinical practice as compared with the BMI. In addition, nutritional status and body composition assessed using the BMI are relatively less precise in liver cirrhosis patients with $\mathrm{HCC}$, in light of the fact that ascetic status could be overestimated in the calculation of BMI. However, malnutrition is the sole impact factor that affects the BMI, and ascites have only a limited effect on the BMI. Furthermore, ascites are one of the important components in the determination of the Child-Pugh score. Our study revealed clear evidence that a higher BMI is associated with better prognosis, although a high Child-Pugh score adversely affected HCC outcome. This suggests that BMI is an appropriate factor in the evaluation of nutritional status, despite its limitations.

Our study was the first to focus on BMI with regard to the prognosis of patients with HCC. However, it had some limitations. First, there was bias because it was a retrospective study. Second, CT data were not available for our patients, and only BMI was evaluated rather than body composition components.

\section{Conclusions}

In conclusion, our data suggest that a lower BMI has a significant impact regarding the poor treatment outcomes of patients with HCC. To better understand the impact of BMI on the prognosis of HCC patients, more large-scale cohort studies will be required.

\section{Competing interests}

The authors declare that they have no competing interests.

\section{Authors' contributions}

QGL participated in the design of the study, performed the statistical analysis, and drafted the manuscript. HX participated in the design of the study and helped to draft the manuscript. DL participated in the follow-up of all of the patients. HL participated in the follow-up of all of the patients. All authors read and approved the final manuscript.

\section{Acknowledgments}

We thanked National Health and Family Planning Commission of the Heilongjiang Province (2014-295); and Funding of First hospital of Harbin Medical University (2014Y010).

\section{Author details}

'Department of Infectious Disease, First Affiliated Hospital of Harbin Medical University, No. 23 You Zheng Street, Harbin 150001, People's Republic of China. ${ }^{2}$ Department of Gastroenterology, Second Affiliated Hospital of Harbin Medical University, Xuefu Road, Harbin 150086, People's Republic of China.

Received: 18 May 2015 Accepted: 22 September 2015

Published online: 06 October 2015

\section{References}

1. Jemal A, Bray F, Center MM, Ferlay J, Ward E, Forman D. Global cancer statistics. CA Cancer J Clin. 2011;61:69-90.

2. Gaujoux S, Torres J, Olson S, Winston C, Gonen M, Brennan MF, et al. Impact of obesity and body fat distribution on survival after pancreaticoduodenectomy for pancreatic adenocarcinoma. Ann Surg Oncol. 2012;19:2908-16.

3. Sinicrope FA, Foster NR, Sargent DJ, O'Connell MJ, Rankin C. Obesity is an independent prognostic variable in colon cancer survivors. Clin Cancer Res. 2010;16:1884-93. 
4. Yoon HH, Lewis MA, Shi Q, Khan M, Cassivi SD, Diasio RB, et al. Prognostic impact of body mass index stratified by smoking status in patients with esophageal adenocarcinoma. J Clin Oncol. 2011;29:4561-67.

5. Caldwell SH, Crespo DM, Kang HS, Al-Osaimi AM. Obesity and hepatocellular carcinoma. Gastroenterology. 2004;127 Suppl 1:S97-103.

6. Bruix J, Sherman M. Management of hepatocellular carcinoma: an update. Hepatology. 2011;53:1020-22.

7. Physical status: the use and interpretation of anthropometry. Report of a WHO expert committee. World Health Organ Tech Rep Ser. 1995. 854:1-452.

8. Liu D, Li Q, Yang Z, Hu X, Qian W, Du Y, et al. Association of body mass index and smoking on outcome of Chinese patients with colorectal cancer. World J Surg Oncol. 2013;11:271-6.

9. Utsunomiya T, Okamoto M, Kameyama T, Matsuyama A, Yamamoto M, Fujiwara $\mathrm{M}$, et al. Impact of obesity on the surgical outcome following repeat hepatic resection in Japanese patients with recurrent hepatocellular carcinoma. World J Gastroenterol. 2008;14:1553-8.

10. Okamura Y, Maeda A, Matsunaga K, Kanemoto H, Uesaka K. Negative impact of low body mass index on surgical outcomes after hepatectomy for hepatocellular carcinoma. J Hepatobiliary Pancreat Sci. 2012;19:449-57.

11. Forner A, Reig ME, de Lope CR, Bruix J. Current strategy for staging and treatment: the BCLC update and future prospects. Semin Liver Dis. 2010;30:61-74.

12. Merli M, Giusto M, Gentili F, Novelli G, Ferretti G, Riggio O, et al. Nutritional status: its influence on the outcome of patients undergoing liver transplantation. Liver Int. 2010;30:208-14.

13. Fujiwara N, Nakagawa H, Kudo Y, Tateishi R, Taguri M, Watadani T, et al. Sarcopenia, intramuscular fat deposition, and visceral adiposity independently predict the outcomes of hepatocellular carcinoma. J Hepatol. 2015;63:131-40.

\section{Submit your next manuscript to BioMed Central and take full advantage of:}

- Convenient online submission

- Thorough peer review

- No space constraints or color figure charges

- Immediate publication on acceptance

- Inclusion in PubMed, CAS, Scopus and Google Scholar

- Research which is freely available for redistribution 